\title{
Pengaruh Hambatan Samping Terhadap Kinerja Ruas Jalan Antang Raya Kota Makassar
}

\author{
Henry. S. M. Pirade ${ }^{* 1}$,Indra .S . Kato ${ }^{* 2}$, Sufiati Bestari ${ }^{* 3}$, Rais Rachman ${ }^{* 4}$ \\ *1,2 Mahasiswa Prodi Teknik Sipil, Universitas Kristen Indonesia Paulus, Makassar, Indonesia \\ pirade70@gmail.com, indrakato843@gmail.com \\ *3,4 Dosen Prodi Teknik Sipil, Universitas Kristen Indonesia Paulus, Makassar, Indonesia \\ rais.rachman@gmail.com
}

\begin{abstract}
ABSTRAK
Ruas perkotaan Jalan Antang Raya ini cukup padat pada waktu tertentu dengan parkir kendaraan dan angkutan umum yang menurunkan penumpang di sepanjang jalan, ditambah jumlah pejalan kaki yang berjalan atau menyeberang sepanjang segmen jalan, dan jumlah kendaraan bermotor yang masuk keluar ke/dari lahan samping jalan serta arus kendaraan yang bergerak lambat. Penelitian ini bertujuan untuk mengetahui apakah hambatan samping adalah penyebab kemacetan pada ruas Jalan Antang Raya, atau arus yang datang ke ruas Jalan Antang Raya yang besar. Hambatan samping yang terjadi pada ruas jalan Antang Raya segmen Misi Depo Bangunan- Stikes Mega Rizky tergolong dalam kelas sangat tinggi dengan rata-rata total puncak hambatan samping sebesar 1289,87 kejadian terbobot. Penyumbang hambatan samping terbesar adalah kendaraan yang keluar masuk bahu jalan dengan presentasi $55,4 \%$, sedangkan pejalan kaki, kendaraan parkir atau berhenti, dan kendaraan lambat dengan total presentasi $44,6 \%$.
\end{abstract}

Kata Kunci : ruas perkotaan; hambatan samping; kendaraan bermotor; pejalan kaki.

\begin{abstract}
The urban section of Jalan Antang Raya is quite dense at certain times with vehicle parking and public transportation which lowers passengers along the road, plus the number of pedestrians walking or crossing along the road segment, and the number of motorized vehicles entering to / from the side road and slow moving vehicles. This study aims to determine whether side barriers are the cause of congestion on the Jalan Antang Raya section, or the flow coming to the large Jalan Antang Raya section. Side frictions that occur on the Antang Raya road segment, the Mission Depot Building - Mega Rizky Stikes are classified as very high class with an average total peak side friction of 1289.87 weighted events. The biggest side contributor is the vehicle that goes in and out of the shoulder with a presentation of $55.4 \%$, while pedestrians, parking vehicles or stops, and slow vehicles with a total presentation of $44.6 \%$.
\end{abstract}

Keywords: urban road; side friction; motorized vehicle; pedestrian.

\section{PENDAHULUAN}

Kemacetan lalu lintas disebabkan oleh ketidakseimbangan antara peningkatan kepemilikan kendaraan dan pertumbuhan prasarana jalan yang tersedia serta kapasitas ruas jalan yang ada lebih kecil dari kapasitas jalan yang direncanakan akibat adanya hambatan di tepi jalan atau sering disebut juga hambatan samping. Hambatan samping tersebut sering terkait dengan adanya aktivitas sosial dan ekonomi, yaitu adanya parkir di badan jalan yang dikarenakan terdapat pertokoan yang tidak menyediakan tempat parkir, sarana angkutan umum yang menurunkan penumpang di sembarang tempat serta lalu lalangnya orang untuk menyeberang yang menyebabkan masalah atau kemacetan..
Hambatan samping sangat mengganggu kelancaran arus lalu lintas. Jalan yang seharusnya digunakan untuk arus lalu lintas tersita untuk kendaraan berhenti. Selain itu trotoar yang seharusnya digunakan untuk pejalan kaki dialihfungsikan, serta banyaknya akses keluar masuk kendaraan dari lahan sepanjang jalan semakin menambah kepadatan pada ruas jalan tersebut.

Pengaruh hambatan samping tersebut terjadi pada sekitar ruas Jalan Antang Raya, kota Makassar. Seharusnya ruas jalan yang dibutuhkan harus sesuai dengan ruas yang ada, karena hambatan samping jalan selalu ada, dan yang harus dikontrol adalah proporsi arus lalu lintas dan kapasitas jalan. 
Faktanya ruas Jalan Antang Raya ini cukup padat pada waktu tertentu dengan parkir kendaraan dan angkutan umum yang menurunkan penumpang di sepanjang jalan. Selain itu ditambah jumlah pejalan kaki yang berjalan atau menyeberang sepanjang segmen jalan, dan jumlah kendaraan bermotor yang masuk keluar ke/dari lahan samping jalan serta arus kendaraan yang bergerak lambat. Hal ini sangat mengganggu kendaraan yang lewat dan menimbulkan kemacetan di ruas jalan Antang Raya.

Tujuan penelitian untuk mengetahui karakteristik hambatan samping dan kontribusi hambatan samping pada kinerja ruas jalan Antang Raya segmen dari Misi Depo Bangunan sampai Stikes Mega Rizky.

Nilai arus lalu lintas $(\mathrm{Q})$ mencerminkan komposisi lalu lintas dengan menyatakan arus dalam satuan mobil penumpang (smp) [1]. Arus lalu lintas terbagi atas arus tak terhenti yaitu hasil interaksi antar kendaraan dan antara kendaraan dengan karakteristik geometris dari sistem jalan, sedangkan arus terhenti terjadi pada fasilitas transportasi dengan mengakibatkan terjadinya pemberhentian secara berkala terhadap arus lalu lintas [2]. Semua nilai arus lalu lintas diubah menjadi satuan mobil penumpang (smp) dengan menggunakan ekivalensi mobil penumpang (emp), dalam hal ini ekivalensi mobil penumpang (emp) untuk masing-masing tipe kendaraan tergantung pada tipe jalan dan arus lalu lintas total yang dinyatakan dalam kend/jam. Setelah dilakukan survey arus lalu lintas dan diketahui arus lalu lintas dalam kend/jam selanjutnya bisa ditentukan nilai ekivalensi mobil penumpang (emp) berdasarkan Tabel 1 berikut.

Tabel 1. Nilai ekivalensi mobil penumpang untuk jalan perkotaan tak terbagi

\begin{tabular}{|c|c|c|c|c|}
\hline \multirow{4}{*}{$\begin{array}{c}\text { Tipe jalan } \\
\text { tak } \\
\text { terbagi }\end{array}$} & \multirow{4}{*}{$\begin{array}{c}\text { Arus lalu } \\
\text { lintas total } \\
\text { dua arah } \\
\text { (kend/jam) }\end{array}$} & \multicolumn{3}{|c|}{ Emp } \\
\hline & & \multirow[t]{3}{*}{ HV } & \multirow{2}{*}{\multicolumn{2}{|c|}{$\begin{array}{c}\text { MC } \\
\text { Lebar jalur } \\
\text { lalu lintas } \mathrm{W}_{\mathrm{C}} \\
(\mathrm{m})\end{array}$}} \\
\hline & & & & \\
\hline & & & $\leq 6$ & $>6$ \\
\hline $\begin{array}{l}\text { Dua-lajur } \\
\text { tak- } \\
\text { terbagi } \\
\text { (2/2 UD) }\end{array}$ & $\begin{array}{l}0 \\
\geq 1800\end{array}$ & $\begin{array}{l}1,3 \\
1,2\end{array}$ & $\begin{array}{l}0,5 \\
0,35\end{array}$ & $\begin{array}{l}0,40 \\
0,25\end{array}$ \\
\hline $\begin{array}{l}\text { Empat- } \\
\text { lajur tak- } \\
\text { terbagi } \\
\text { (4/2 UD) }\end{array}$ & $\begin{array}{l}0 \\
\geq 1800\end{array}$ & $\begin{array}{l}1,3 \\
1,2\end{array}$ & $\begin{array}{l}0,40 \\
0,25\end{array}$ & \\
\hline
\end{tabular}

Secara matematis, arus lalu lintas dinyatakan dengan persamaan :

$Q_{s m p}=(e m p L V \times$ jumlah LV) $+(e m p H V \times$ jumlah

$\mathrm{HV})+($ emp MC x jumlah MC)

\section{Hambatan Samping}

Hambatan samping adalah dampak terhadap kinerja lalu lintas dari aktivitas samping segmen jalan, seperti: Pejalan kaki yang berjalan atau menyebrang sepanjang segmen jalan, angkutan umum dan kendaraan lain yang berhenti dan parkir, arus kendaraan yang bergerak lambat, dan kendaraan yang keluar masuk disamping jalan [1].

\section{Kapasitas Jalan}

Kapasitas jalan adalah jumlah kendaraan maksimum yang dapat melewati satu jalur atau ruas jalan selama periode waktu tertentu dalam kondisi jalan raya dan arus lalu lintas tertentu.

Persamaan umum untuk menghitung kapasitas ruas jalan untuk daerah perkotaan adalah [1]:

$C=C_{0} \times F C_{w} \times F C_{S P} \times F C_{S F} \times F C_{C S}$

dengan $\mathrm{C}=$ kapasitas jalan (smp/jam), $\mathrm{C}_{0}=$ kapasitas dasar (smp/jam), $\mathrm{FCw}=$ faktor penyesuaian lebar jalur lalu lintas, $F C_{S P}=$ faktor penyesuaian pemisah arah, $\mathrm{FC}_{\mathrm{SF}}=$ faktor penyesuaian hambatan samping, dan $\mathrm{FC}_{\mathrm{CS}}=$ faktor penyesuaian ukuran kota.

\section{Kinerja Jalan}

Kinerja ruas jalan dapat ditunjukkan dengan nilai V/C (derajat kejenuhan), kecepatan perjalanan rata-rata, dan tingkat pelayanan [3].

\section{a. Derajat Kejenuhan}

Derajat kejenuhan (degree of saturation $=\mathrm{DS}$ ) $\mathrm{di}$ defenisikan sebagai rasio arus lalu lintas (smp/jam) terhadap kapasitas (smp/jam) pada bagian jalan tertentu, digunakan sebagai faktor utama dalam penentuan tingkat kinerja simpang dan ruas jalan. Nilai DS merupakan besaran dasar yang menentukan kinerja lalu lintas [1].

$D S=\frac{Q}{C}$

dengan DS = Derajat kejenuhan, $Q=$ Arus lalu

lintas, dan $\mathrm{C}=$ Kapasitas jalan

\section{Kecepatan Arus Bebas}

Kecepatan arus bebas didinisikan sebagai kecepatan pada saat tingkatan arus nol. Persamaan untuk penentuan kecepatan arus bebas pada jalan perkotaan sebagai berikut [1] :

$F V=\left(F V_{0}+F V_{w}\right) \times F F V_{S F} \times F F V_{C S}$

dengan : FV = kecepatan arus bebas kendaraan ringan $(\mathrm{km} / \mathrm{jam}), \quad F V_{O}=$ kecepatan arus bebas dasar $(\mathrm{km} / \mathrm{jam}), \quad \mathrm{FV}_{\mathrm{w}}=$ faktor penyesuaian kecepatan arus bebas $(\mathrm{km} / \mathrm{jam}), F F V_{S F}=$ faktor penyesuaian hambatan samping, $F F V_{C S}=$ faktor penyesuaian ukuran kota. 


\section{b. Kecepatan Rata-rata Kendaraan Ringan}

Kecepatan rata-rata kendaraan ringan adalah kecepatan rata-rata kendaraan untuk menempuh ruang yang sedang dianalisis. Nilai kecepatan ratarata ruang dipengaruhi oleh derajat kejenuhan dan kecepatan arus bebas [1].

\section{c. Kecepatan Aktual Kendaraan Ringan}

Kecepatan adalah laju perjalanan yang biasanya dinyatakan dengan satuan kilometer per jam $(\mathrm{km} / \mathrm{jam})$, dipilih kendaraan ringan saat survey kecepatan kendaraan karena kendaraan ringan yang mewakili populasi kendaraan. Di MKJI digunakan istilah $V_{L v}$, Tetapi data pengamatan yang lebih mewakili diambil dari banyak kendaraan ringan yang dirata-ratakan kecepatannya sehingga dikatakan kecepatan rata-rata kendaraan ringan [1]. Dan rumus kecepatan adalah

$\mathrm{V}=\mathrm{S} / \mathrm{t}$

dengan $\mathrm{V}=$ Kecepatan, $\mathrm{S}=$ Jarak, $\mathrm{t}=$ Waktu

\section{Penelitian Terdahulu}

Kecepatan kendaraan mengalami penurunan dengan meningkatnya hambatan samping pada volume lalu lintas, sedangkan pada volume kendaraan yang rendah, penurunan keccepatan kendaraan akibat hambatan samping tidak terlalu signifikan [4].

Pengaruh hambatan samping pada jalan arteri dilakukan dengan menggunakan tiga model dasar, yaitu tidak terdapat hambatan untuk kondisi jalan dengan geometris yang ideal, kedua hambatan samping akibat aktivitas parkir, pergerakan pejalan kaki, kendaraan berat yang bergabung dalam arus lalu lintas. Skenario dilakukan untuk jumlah lajur 1,2, dan 3, serta arus lalu lintas dari kondisi rendah hingga tinggi, dimana arus dan keccepatan dimodelkan menggunakan perangkat lunak AIMSUN , dengan hasil terdapat pengaruh negatif untuk kapasitas jalan akibat hambatan samping terhadap kecepatan arus bebas dan kecepatan rata-rata [5].

Studi pengaruh hambatan samping (tempat pemberhentian bis, pejalan kaki, dan aktivitas parkir kendaraan) di kota padat penduduk (Mumbai, Bengaluru, dan Thiruvananthapuram), India, dengan menggunakan metode analisis regresi linier berganda menghasilkan terdapat dampak yang signifikan dari hambatan samping pada kecepatan kendaraan ruas perkotaan [6].

Pengaruh hambatan samping pada persimpangan bersinyal (studi kasus Simpang Tanah Jua) dengan metoda program komputer didapatkan nilai kapasitas $1480 \mathrm{smp} / \mathrm{jam}$, derajat kejenuhan 1,065, angka henti 5,245 berhenti/smp, tundaan geometrik 7,9 det/smp, tundaan total $713,6 \mathrm{det} / \mathrm{smp}$, dan panjang antrian $615 \mathrm{~m}[7]$.
Penelitian tentang pengaruh hambatan samping terhadap kinerja jalan, biaya operasional kendaraan dan biaya kemacetan Jalan Gatot Subroto Kota Malang dengan menggunakan metode analisis regresi linier berganda dengan hasil model regresi BOK yang dipengaruhi kendaraan masuk, keluar, dan melambat yaitu $Y=0,224+0,003 X_{1}-0,001 X_{2}$ $+0,006 X_{3}$, BOK yang dipengaruhi oleh pejalan kaki $Y=33,242+2,209 X_{4}$, sedangkan BOK yang dipengaruhi oleh kendaraan masuk, keluar, dan parkir $Y=20,718+0,430 X_{1}+0,300 X_{2}+0,124 X_{3}$ [8].

Pengurangan leber efektif jalan berdasarkan pengaruh hambatan samping yang meningkatkan kemacetan dan mengakibatkan penurunan tingkat layanan ruas perkotaan di Kota Dakha [9].

\section{METODOLOGI PENELITIAN}

Penelitian dilakukan di ruas jalan Antang Raya Kota Makassar, segmen dari Misi depo bangunan sampai Stikes Mega Rizky, dengan panjang jalan 200 m (untuk survey hambatan samping), lebar jalan : 5 m (2 jalur), tipe jalan : Dua jalur dua arah tak terbagi (2/2 UD)

\section{Pengumpulan Data}

Jenis data yang digunakan dalam penulisan ini adalah data primer atau data inti/pokok dan data sekunder atau data pendukung. Data primer adalah data yang diambil langsung di lokasi survey berupa data arus lalu lintas, data hambatan samping, data geometrik jalan, serta data survey kecepatan. Sedangkan untuk pengumpulan data sekunder mencakup peta lokasi survey dan jumlah penduduk Kota Makassar.

\section{a. Data Primer}

Pengambilan data primer dilakukan selama 1 minggu, dan data yang dikumpulkan yaitu data arus lalu lintas dengan cara mencatat jenis-jenis kendaraan yang melintas seperti kendaraan ringan, kendaraan berat, sepeda motor dan kendaraan tidak bermotor dan jumlahnya di ruas jalan yang diamati dalam satuan (kend/jam), dengan interval waktu survey yang digunakan berdasarkan faktor variasi tingkat lalu lintas per 15 menit dalam satu jam, ditetapkan berdasarkan perbandingan antara volume lalu lintas dalam 1 jam dengan empat kali volume lalu lintas per 15 menit, dan setelah diketahui jenis dan jumlah kendaraan yang melintas tersebut, nilai ekivalensi mobil penumpang berguna untuk mengubah satuan (kend/jam) menjadi (smp/jam) . Selanjutnya data yang dikumpulkan yaitu data hambatan samping, yang dilakukan dengan cara mencatat jumlah kendaraan yang berhenti atau parkir, kendaraan yang keluar masuk pada samping jalan, pejalan kaki atau penyeberang jalan di sepanjang ruas jalan antang raya. Selanjutnya data 
geometrik jalan untuk mengetahui lebar jalan dan lebar bahu jalan yang akan digunakan untuk menghitung kapasitas jalan, yaitu survey kecepatan untuk mengetahui kecepatan rata-rata kendaraan ringan, Survey ini dilakukan dengan cara pengamatan langsung. Kecepatan kendaraan dihitung dengan melewati dua titik yang telah ditentukan, titik awal dimulai dari STA \pm 0 dan titik akhir STA \pm 50 survey dilakukan setiap lima belas menit dan rata-rata kecepatan diambil untuk periode per jam.

\section{b. Data Sekunder}

Data sekunder yang diperlukan adalah peta lokasi survey dan juga jumlah penduduk Kota Makassar, yang akan digunakan untuk menghitung kapasitas jalan.

\section{Pos Pengamatan}

Untuk mengumpulkan data arus lalu lintas, data hambatan samping, serta kecepatan rata-rata kendaraan ringan diperlukan pos pengamatan guna mempermudah pencatatan data tersebut. Adapun pos-pos yang dimaksudkan antara lain :

\section{a. Pos Pertama (Survei Arus Lalu lintas)}

Pada pos survey arus lalu lintas yang disurvey adalah jumlah kendaraan yang tergolong dalam empat golongan kendaraan [1], yaitu kendaraan berat (truk dan bus), kendaran ringan (mobil penumpang, mini bus, pick-up, truk kecil, dan jeep), dan sepeda motor termasuk kendaraan bermotor beroda tiga .

Pos survey arus lalu lintas terbagi atas 2 pos, pos pertama letaknya pada sta $0+000$, dan pos kedua pada sta $0+200$. Pada setiap pos diperlukan 2 surveyor, dan tugas surveyor pertama yaitu mensurvey kendaraan ringan dan berat, dan surveyor kedua mensurvey kendaraan bermotor, pembagian tugas ini berlaku untuk kedua pos arus lalu lintas menggunakan hand counter.

\section{b. Pos Kedua (Hambatan Samping)}

Pada pos ini yang akan disurvei adalah hambatan samping yang terbagi atas empat yaitu pejalan kaki, kendaraan parkir atau berhenti, kendaraan masuk atau keluar bahu jalan, serta kendaraan lambat [1]. Pos survey hambatan samping terbagi atas 4 pos untuk 1 jalur, jadi total 8 pos untuk dua jalur pos pertama letaknya pada sta $0+025$ dan jumlah surveyor pada pos ini sebanyak dua surveyor yang akan mensurvei hambatan samping sepanjang $50 \mathrm{~m}$ dari sta $0+000$ - sta 0+050, selanjutnya pos kedua pada sta $0+075$, dan jumlah surveyor pada pos ini sebanyak dua surveyor yang akan mensurvei hambatan samping sepanjang $50 \mathrm{~m}$ dari sta 0+050 sta $0+100$, selanjutnya pos ketiga pada sta $0+125$, jumlah surveyor pada pos ini sebanyak dua surveyor yang akan mensurvei hambatan samping sepanjang $50 \mathrm{~m}$ dari sta $0+100$ - sta $0+150$, dan terakhir pos keempat pada sta $0+175$, dan jumlah surveyor pada pos ini sebanyak dua surveyor yang akan mensurvei hambatan samping sepanjang $50 \mathrm{~m}$ dari sta $0+150-$ sta $0+200$, pembagian pos ini berlaku untuk kedua jalur (arah ke gowa dan arah ke PLTU) dan berdasarkan pembagian surveyor terdapat masingmasing 2 surveyor di setiap pos yang tugasnya sama yaitu, surveyor pertama yaitu mensurvey pejalan kaki dan kendaraan parkir atau berhenti, dan surveyor kedua mensurvey yang keluar masuk jalan, dan kendaraan lambat, yang tergolong dalam kendaraan lambat yaitu kendaraan tak bermotor (seperti gerobak, sepeda). Pembagian tugas ini berlaku untuk kedua pos pada pos hambatan samping, dan menggunakan alat hand counter. Pada survey hambatan samping dilakukan survey keseluruhan bersamaan dengan survey arus lalu lintas, dan pada hari selanjutnya dilakukan survey hanya pada saat arus puncak saja.

\section{c. Pos Ketiga (Survey Kecepatan)}

Pada pos ini yang akan disurvey adalah kecepatan aktual rata-rata kendaraan ringan. Pada pos survey kecepatan terbagi atas 2 pos, pos pertama letaknya pada sta 0+000 dan pos kedua letaknya sta 0+050, yang akan disurvey dilapangan adalah waktu tempuh kendaraan ringan dalam 50 meter, dan jenis kendaraan yang disurvey yaitu kendaraan ringan karena lebih mewakili, sebab jika kendaraan berat kecepatannya rendah dikarenakan ukuran dari kendaraan ini, dan jika sepeda motor kecepatannya tinggi dan bisa melakukan manuver mendahului kendaraan lain sehingga tidak bisa mewakili, maka diambil kendaraan ringan untuk survey kecepatan .

\section{HASIL DAN PEMBAHASAN}

\section{Arus Lalu Lintas}

Selama tujuh hari pengamatan, diperoleh arus puncak pada hari senin, 1998,5 smp/jam, sedangkan hari minggu memiliki arus terendah, sebesar 717,6 smp/jam. Rata-rata arus lalulintas selama waktu pengamatan adalah 1653,2 smp/jam. Untuk lebih jelasnya, rata-rata arus puncak selama tujuh hari pengamatan dapat dilihat pada Tabel 2 .

Tabel 2. Rata-rata arus puncak pengamatan

\begin{tabular}{cc}
\hline Hari Pengamatan & Total 2 arah (smp/jam) \\
\hline Senin & 1998,5 \\
\hline Selasa & 1993,4 \\
\hline Rabu & 1744,6 \\
\hline Kamis & 1914,8 \\
\hline Jumat & 1791,8
\end{tabular}




\begin{tabular}{cc}
\hline Sabtu & 1472 \\
\hline Minggu & 717,6 \\
\hline Total $(\mathrm{Q})$ & $\mathbf{1 1 5 7 2 , 7}$ \\
\hline Rata-rata & $\mathbf{1 6 5 3 , 2}$ \\
\hline
\end{tabular}

\section{Hambatan Samping}

Jumlah hambatan samping tertinggi pada ruas jalan Antang Raya segmen Misi Depo Bangunan- Stikes Mega Rizky terdapat pada hari senin, sebesar 1496,7 per $200 \mathrm{~m}$, dan terendah pada hari minggu, sebesar 985,6 per $200 \mathrm{~m}$. Rata-rata jumlah hambatan samping dengan kejadian per $200 \mathrm{~m}$ adalah 1289,87 tergolong dalam hambatan samping kelas tinggi. Rata-rata hambatan samping selama pengamatan dapat dilihat pada Tabel 3.

Tabel 3. Rata-rata hambatan samping selama 7 hari

\begin{tabular}{cc}
\hline $\begin{array}{c}\text { Hari } \\
\text { Pengamatan }\end{array}$ & $\begin{array}{c}\text { Jumlah terbobot Kejadian per } \\
\mathbf{2 0 0} \mathbf{~} \text { (dua sisi) D1-D7 }\end{array}$ \\
\hline Senin & 1496,7 \\
\hline Selasa & 1339,9 \\
\hline Rabu & 1390,7 \\
\hline Kamis & 1283,1 \\
\hline Jumat & 1317,3 \\
\hline Sabtu & 1215,8 \\
\hline Minggu & 985,6 \\
\hline Total & $\mathbf{9 0 2 9}$ \\
\hline Rata-rata & 1289,87 \\
\hline
\end{tabular}

\section{Kapasitas Jalan}

Analisis kapasitas aktual jalan yang digunakan adalah mengacu pada MKJI 1997 dengan menggunakan persamaan (2), dimana

Co $=2900$ (Kapasitas dasar per lajur (smp/jam), untuk tipe jalan 2/2 [1]

$\mathrm{FC}_{\mathrm{w}}=0,56$ ( faktor penyesuain lebar jalur lalu lintas untuk tipe jalan dua arah dengan lebar lajur efektif $\mathrm{Wc}=5 \mathrm{~m}$ ) [1].

$\mathrm{FC}_{\mathrm{SP}}=0,988$ Untuk perbandingan (52\%-48\%) digunakan interpolasi dari tabel 2.4, sehingga $\mathrm{FC}_{S P}=1-\frac{1}{2}(1-0,97)=0,988$, (untuk tipe jalan dua arah [1]).

$\mathrm{FC}_{\mathrm{SF}}=0,79$ (faktor penyesuain hambatan samping dengan lebar bahu tipe jalan 2/2 UD hambatan samping $\mathrm{VH}=$ Very High [1].

$\mathrm{FCcs}=1,0$ (faktor penyesuain ukuran kota, Kota Makassar berpenduduk 1.469.601 juta jiwa).

$\mathrm{C}=\mathrm{Co}_{\mathrm{F}} \mathrm{FCW} \times \mathrm{FC}_{\mathrm{SP}} \times \mathrm{FC}_{\mathrm{SF}} \times \mathrm{FC}_{\mathrm{CS}}$

$=2900 \times 0,56 \times 0,988 \times 0,79 \times 1$

$=1257,3 \mathrm{smp} / \mathrm{jam}$

\section{Derajat Kejenuhan}

Derajat kejenuhan dapat dihitung dengan menggunakan persamaan (3) yaitu :

$Q=1653,2 \mathrm{smp} / \mathrm{jam}$

C $=1257,3 \mathrm{smp} / \mathrm{jam}$, yaitu kapasitas aktual jalan.

Derajat kejenuhan (DS) pada kondisi arus puncak sehari-hari.

$$
\begin{array}{ll}
\mathrm{DS}=\quad & \mathrm{Q} / \mathrm{C} \\
\frac{1653,2 \mathrm{smp} / \mathrm{jam}}{1257,3 \mathrm{smp} / \mathrm{jam}} \\
1,3
\end{array}
$$

Nilai derajat kejenuhan yang lebih besar dari pada 0,75 menunjukkan kondisi arus lalu lintas macet.

\section{Kecepatan Arus Bebas}

Dalam menentukan kecepatan arus bebas, maka digunakan persamaan (4)

dimana FV = kecepatan arus bebas kendaraan ringan pada kondisi lapangan $(\mathrm{km} / \mathrm{jam}), \mathrm{FV}_{\mathrm{O}}=$ $(44 \mathrm{~km} / \mathrm{jam})$, kecepatan arus bebas dasar kendaraan ringan [1], $\quad \mathrm{FV}_{\mathrm{w}}=(-9,5 \mathrm{~km} / \mathrm{jam})$, faktor penyesuaian kecepatan arus bebas untuk lebar Jalur lalu lintas [1], FFV $V_{S F}=(0,79)$,faktor penyesuaian hambatan samping [1], FFV $=$ (1), faktor penyesuaian ukuran kota [1],

Maka diperoleh kecepatan arus bebas :

$$
\begin{aligned}
\mathrm{FV} & =\left(F V_{0}+F V_{\mathrm{w}}\right) \times F F V_{S F} \times F F V_{C S} \\
& =(44+(-9,5) \times 0,79 \times 1 \\
& =27,255 \mathrm{~km} / \mathrm{jam}
\end{aligned}
$$

\section{Kecepatan Aktual Kendaraan Ringan}

Kecepatan rata-rata kendaraan ringan pada pengamatan hari senin sebesar $9.356 \mathrm{~km} / \mathrm{jam}$, ini disebabkan banyaknya volume kendaraan disertai dengan hambatan samping yang tinggi sehingga mempengaruhi kecepatan kendaraan. Kecepatan rata-rata kendaraan ringan mengalami peningkatan selama hari pengamatan. Hari minggu memperlihatkan kecepatan rata-rata kendaraan ringan adalah $29.545 \mathrm{~km} / \mathrm{jam}$. Total rata-rata kecepatan kendaraan ringan selama hari pengamatan adalah $15.646 \mathrm{~km} / \mathrm{jam}$. Untuk lebih jelasnya, kecepatan ratal-rata kendaraan ringan selama hari pegamatan disajikan pada Tabel 4.

Tabel 4. Kecepatan rata-rata kendaraan ringan pengamatan hari senin

\section{No Hari Kecepatan rata-rata kendaraan ringan}

(km/jam)

$1 \quad$ Senin $\quad 9.356$




\begin{tabular}{ccc}
\hline 2 & Selasa & 9.657 \\
\hline 3 & Rabu & 14.400 \\
\hline 4 & Kamis & 13.959 \\
\hline 5 & Jumat & 14.500 \\
\hline 6 & Sabtu & 16.828 \\
\hline 7 & Minggu & 29.545 \\
\hline \multicolumn{2}{c}{ Jumlah } & 108.246 \\
\hline Rata-rata & $\mathbf{1 5 . 4 6 4}$ \\
\hline
\end{tabular}

\section{Pengaruh Hambatan Samping Terhadap Kinerja Ruas Jalan}

Untuk nilai koefisien korelasi dan koefisien determminasi dari hasil analisa konstribusi hambatan samping didapatkan nilai korelasi $(R)=0.0744$ hal ini menunjukkan bahwa ada keeratan hubungan antara kecepatan kendaraan dengan hambatan samping yang ada.Koefisien determinasi $\left(R^{2}\right)$ yang diperoleh dari hasil analisis di atas sebesar $=0.554$ hal ini menunjukkan bahwa $55.4 \%$ perubahan variabel kendaraan keluar masuk lokasi penelitian, sehingga $45 \%$ merupakan variabel kendaraan berhenti, pejalan kaki, dan kendaraan lambat.

\section{KESIMPULAN}

Hambatan samping yang terjadi pada ruas jalan Antang Raya segmen Misi depo Bangunan- Stikes Mega Rizky tergolong dalam kelas "sangat tinggi" dengan rata-rata total puncak hambatan samping sebesar 1289,87 kejadian terbobot. Berdasarkan analisis kontribusi hambatan samping, penyumbang hambatan samping terbesar adalah kendaraan yang keluar masuk bahu jalan dengan presentasi $55,4 \%$, sedangkan pejalan kaki, kendaraan parkir atau berhenti, dan kendaraan lambat dengan total presentasi $44,6 \%$.

\section{DAFTAR PUSTAKA}

[1] "(PDF) Manual Kapasitas Jalan Indonesia ( MKJI ) | ketut mertayasa - Academia.edu." [Online]. Available:

https://www.academia.edu/16746001/Manual_Ka pasitas_Jalan_Indonesia_MKJI_.
[2] "(PDF) Dasar-dasar Rekayasa Transportasi | Libunelo Rahmat - Academia.edu.” [Online]. Available:

https://www.academia.edu/37169594/Dasardasar_Rekayasa_Transportasi.

[3] "(PDF) Perencanaan dan Pemodelan Transportasi | Mutia Ayuni - Academia.edu." [Online]. Available: https://www.academia.edu/27296462/Perencana an dan Pemodelan Transportasi.

[4] "(PDF) Analysis of Side Friction on Urban Arterials." [Online]. Available: https://www.researchgate.net/publication/324479 597_Analysis_of_Side_Friction_on_Urban_Arteri als.

[5] "Application of AIMSUN Microscopic Simulation Model in Evaluating Side Friction Impacts on Traffic Stream Performance." [Online]. Available: https://publications.waset.org/10009937/applicati on-of-aimsun-microscopic-simulation-model-inevaluating-side-friction-impacts-on-traffic-streamperformance.

[6] S. Salini, S. George, and R. Ashalatha, "Effect of Side Frictions on Traffic Characteristics of Urban Arterials," Transp. Res. Procedia, vol. 17, pp. 636-643, 2016.

[7] "Pengaruh Hambatan Samping Pada Persimpangan Bersinyal (Study Kasus : Simpang Tanah Jua Bukit Tinggi) | Oktavianus | Abstract of Undergraduate Research, Faculty of Civil and Planning Engineering, Bung Hatta University." [Online]. Available: http://ejurnal.bunghatta.ac.id/index.php?journal= JFTSP\&page $=$ article\&op $=$ view\&path $\% 5 B \% 5 D=9$ 681.

[8] S. Permana, A. Wicaksono, L. Djakfar, and J. M. Haryono, "Pengaruh Hambatan Samping Terhadap Kinerja Jalan, Biaya Operasional Kendaraan Dan Biaya Kemacetan Jalan Gatot Subroto Kota Malang," vol. 8, p. 12, 2016.

[9] Md. Mofizul Islam, "Cause of Reduction of Effective Roadway Width Due to Side Friction in Dhaka City," Am. J. Traffic Transp. Eng., vol. 3, no. 1, p. 6, 2018. 